\title{
Evaluation of the Impacts of Land Use on Storm Water Quality: Case Study from Western Australia
}

\author{
Ranjan Sarukkalige, Shane Priddle, and Dinushi Gamage
}

\begin{abstract}
This study evaluates the impacts of land use on storm water quality. Storm water samples were collected from three main land use areas; residential, commercial and industrial lands around the Town of Victoria Park in Western Australia. Each sample was tested to measure important water quality parameters. Time variation of storm water flow, rainfall intensity and storm water quality clearly showed that the highest concentration of pollutants in storm water occurs during the first flush event. Further analysis shows that the commercial storm water demonstrated the cleanest appearing storm water with lowest amounts of suspended solids whereas the industrial storm water had the dirtiest appearing storm water quality. Nutrients in the residential storm water have the lowest nitrate, ammonia and phosphate concentrations. Overall, the industrial land use site recorded the worst storm water quality. Study further provides recommendations for water quality improvement and management controls.
\end{abstract}

Index Terms-Storm water, land use, water quality, pollutants, water quality management.

\section{INTRODUCTION}

The forms and concentrations of contaminants from runoff are closely related to various types of land use because human activity is different according to land use [1], [2]. Storm water runoff picks up natural and human-made contaminants that accumulated on surfaces during the dry days and transports them to the receiving waters bodies such as rivers, lakes and ocean. Development of innovative land-use-related control strategies will be required to control storm water pollution effectively. An approach that could differentiate land-use effects on storm water would be a first step in solving this problem. Several studies have shown that the contribution of storm water pollutants must be considered in order to correctly implement an environmental preservation method for a receiving water body A common objective of most urban water quality studies has been to strive to relate land use to pollutant loadings [3] - [6]. Most of the urban pollutants are initiated from impervious street surfaces; Heavy metals are one of the pollutants generate

Manuscript received September 28, 2011, revised October 30, 2011

Ranjan Sarukkalige is with Department of Civil Engineering, Curtin University, GPO Box U1987, Perth, Western Australia (e-mail: P.Sarukkalige@curtin.edu.au).

Shane Priddle is with Infrastructure Design Branch, Water Corporation, 629, Newcastle Street, Leederville WA 6007 Australia (e-mail: S.Priddle@watercorporation.com.au.)

Dinushi Gamage is with Tactical Asset Management, Water Corporation, 629, Newcastle Street, Leederville WA 6007 Australia (e-mail: D.Gamage@watercorporation.com.au.) from industrial and commercial activities [7], [8]. Nutrients introduced to environment by landscape maintenance activities in both residential and commercial lands [9], [10].

Storm water quality is an issue in Western Australia because the states storm water typically flows into the state's rivers and ocean or infiltrates back into the groundwater system which is used for drinking in the state. Currently in Western Australia, there are no storm water quality management procedures in place. Regional reports show that state storm water may contain different substances including heavy metals, nutrients, petroleum hydrocarbons, suspended solids and microbiological organisms, all depending on the land use of that area. The problem of storm water pollution is becoming worse because of population growth, which results in increased impermeable surfaces. Perth experienced its highest population growth rate in 2007-2008 of $2.8 \%$ [11]. With these increases the quality of storm water is becoming more of an issue around the state as general water quality awareness increases. This study aims to explore the relationship between water quality variables and various types of land use in Western Australia.

\section{Methodology}

The main scopes of this study are; collecting storm water samples from different land use areas over a period of time during a storm event, identifying the storm water quality for different land use areas by analyzing collected samples, studying the temporal variation of storm water quality during a storm event, developing relationships between storm water quality versus land use type and developing recommendations and guidelines for storm water management.

Therefore the methodology mainly followed storm water sample collection from different land use catchments and water quality testing at laboratories. Correct collection of storm water samples is essential to be able to analyze the storm water quality in the laboratory facilities. Once a storm water drainage outlet starts flowing during a storm event, a 1.5 litre sample was taken at ten minute intervals to provide a time related view of the storm water quality. Each sample was tested within $24 \mathrm{hrs}$ of collection. Sample testing was undertaken at the Water Quality laboratory of Curtin University and all testing was conducted according to the test methods specified in APHA, Standard Methods for the Examination of Water and Wastewater [12]. Event samples collected at each study location were analyzed for total organic carbon (TOC), suspended solids (SS), total nitrogen $(\mathrm{TN})$, Nitrate Nitrogen $\left(\mathrm{NO}_{3}^{-}\right)$, Nitrite Nitrogen $\left(\mathrm{NO}_{2}^{-}\right)$, Ammonia Nitrogen $\left(\mathrm{NH}_{3}-\mathrm{N}\right)$ and total phosphorus (TP). An 
electronic rain gauge with a data logger was used to record the rain intensity for each storm event while the storm water samples are collected. In addition the volumetric flow rate of the storm water outlet was also recorded for the duration of the sampling.

\section{StUdy AREA AND LAND USE SELECTION}

As main target of the study is to evaluate the storm water quality in different land use areas, study area should included different land use patterns distributed in closer locations. Town of Victoria Park is an urban area which consists of variety of land use patterns such as residential, commercial and industrial sites located closer distances. Therefore Town of Victoria Park has been selected as the suitable and convenient study area for this study.

Town of Victoria Park is located $3 \mathrm{~km}$ southeast of Perth; it has an area of $17.62 \mathrm{~km} 2$ which consists of mainly commercial and residential areas, also minority of industrial area [13]. The land use areas focused on in this study include residential, commercial and industrial lands around the Town of Victoria Park in Western Australia.

Five sampling locations with varying land uses as shown in Fig 1 have been used for this study; commercial (Site \# 2), residential (Site \# 1), industrial (Site \# 5), and two areas with mix land use patterns (Site \#4 consists of $71 \%$ of residential and $29 \%$ of commercial; Site \#3 consists of $36 \%$ of residential and $64 \%$ commercial). Storm water samples were collected at drainage outlets of the compensation basins of each study area. These outlets were selected based on the surrounding land use, ease of access, site safety and storm water drainage outlet type so that sample collection would be possible.

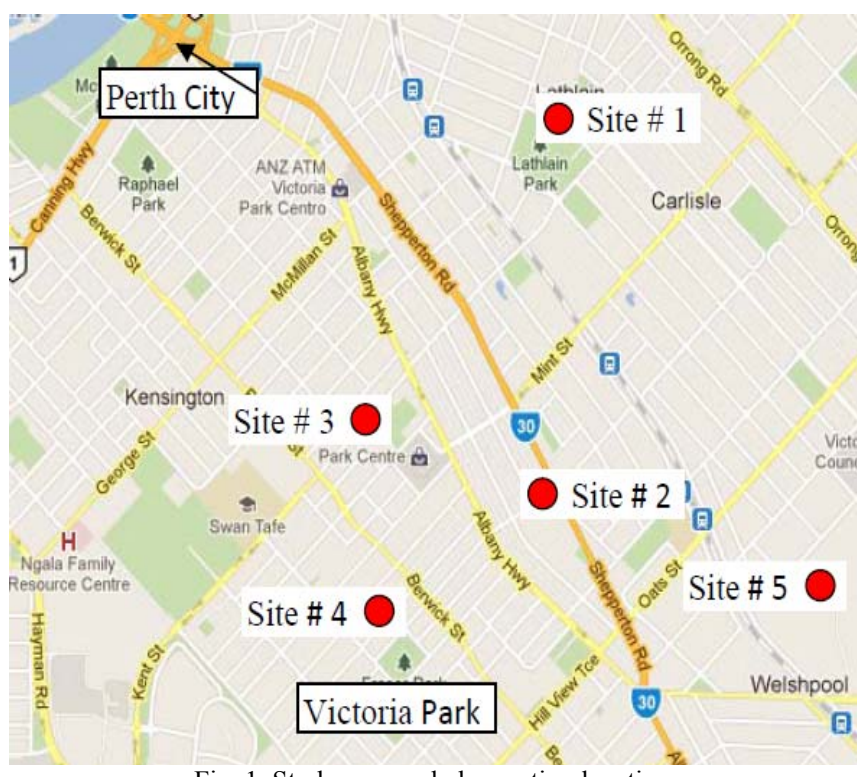

Fig. 1. Study area and observation locations.

\section{Temporal VARIATION OF StORM WATER QUALity}

Temporal change of storm water quality is important to understand the first flush concept and develop storm water quality control methods to separate the first flush. It also gives and estimation on how the temporal relationships among storm water quality, rainfall change and flow rate change. Therefore temporal change of storm water quality was evaluated using the sample collected at every 10mins interval. Fig 2 shows the investigated temporal variation of storm water quality highlighting the temporal variation of Nutrients at commercial, residential and industrial land use observation locations. Also the rainfall intensity has been also integrated in the figures to show the responses of rainfall on water quality. The first flush principle is well demonstrated in these figures, when the highest amount of pollutant concentration occurs at the beginning of the storm event. Other peaks in pollutant concentrations occur in correlation with the maximum peaks in rainfall intensity. This demonstrates the amount of pollutants increase in storm water with relation to intensity of the storm events.

When compare the Nutrient at different land use catchments, commercial land use receives the peak concentration of phosphate 10 minutes after the peak rainfall intensity. Other Nutrients at commercial lands are relatively low compared to phosphate. This is likely to be due to the amount of vehicle use as the majority of this area is used for car parking, contributing to the higher amounts of phosphate. Nutrient concentration levels in the residential land use area also follow the rain intensity pattern by having the highest concentrations recorded simultaneous with the highest rain intensity. Nitrate levels appear to have the opposite occurring by decreasing during the increasing of rain intensity. Ammonia is at its highest concentration with the first flush of storm water and then only small amounts are recorded afterwards for the remainder of the storm event. Phosphate is the most common nutrient in residential land use storm water, having a high concentration with the first flush and then remaining high.

In the industrial land use area, Ammonia and phosphate followed the same pattern. In this site, nitrate concentration levels follow the opposite pattern to the ammonia concentration levels. As nitrate levels increase there is a decrease in both ammonia and phosphate concentration levels. The opposite happens when nitrate levels decrease. Nitrate concentrations decreases when rain intensity increases. This site recorded very small concentrations of nitrite for the whole duration of the storm event demonstrating nitrite is not an issue in this industrial land use area.

Suspended solid is one of the main indicators of water quality. Most of pollutants coagulate with suspended solids and shows great relation with it. Time variation of storm water flow rate and suspended solids is shown in Fig 3. The first flush principle is also demonstrated here. The first flush and other peaks of suspended solids during the storm duration correlate to the increase in storm water flow at the same time. The highest amount of suspended solids concentration occurs at the beginning of the storm event. Other peaks in suspended solids concentrations occur in correlation with the maximum flow. 


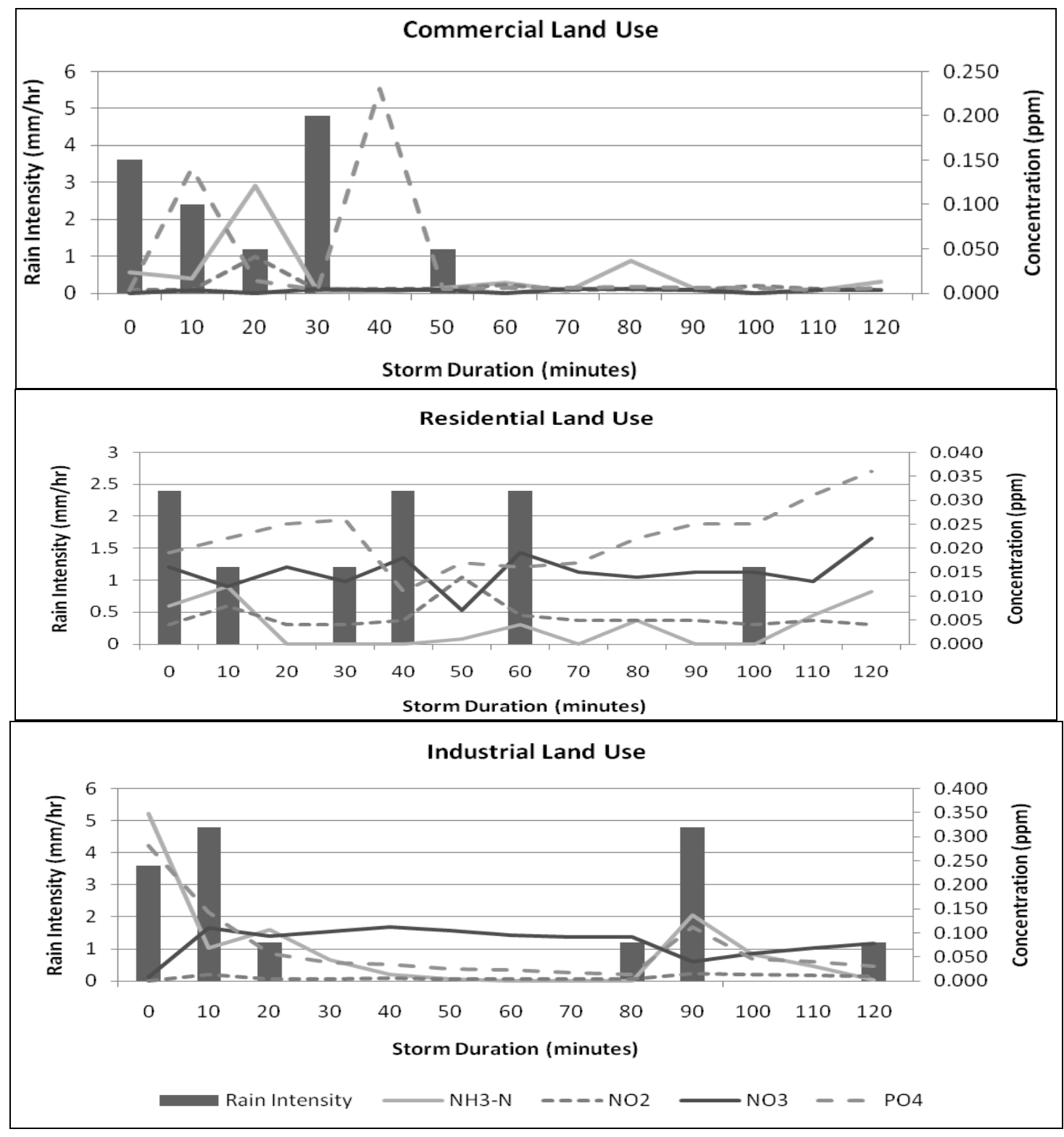

Fig. 2. Temporal variation of nutrient concentrations and rain intensity.

\section{LAND USE VERSUS STORM WATER QUALITY}

To investigate the storm water quality change with catchment land use patterns, the study focused to analyze the storm water quality in different land use areas. Three selected main land use patterns; residential, industrial and commercial land uses areas were considered for the further assessment. The combined land use catchments were not taken into account to develop land use-storm water quality relationships. Same water quality parameters were considered to assess the land use impacts on storm water quality.

Analyzing the pollutant distribution in all collected samples, the average pollutant concentration $(\mathrm{pH}$, suspended solids, Turbidity, Nitrate, Nitrite, Ammonia and Pho in each land use area is tabulated in Table I.

TABLE I: AVERAGE STORM WATER QUALITY RESULTS

\begin{tabular}{cccccccc}
\hline \hline Land use & $\mathrm{pH}$ & $\mathrm{SS}$ & Turbidity (NTU) & Nitrite (ppm) & Nitrate (ppm) & Ammonia (ppm) & Phosphate (ppm) \\
\hline Commercial & 5.74 & 0.007 & 1.164 & 0.008 & 0.003 & 0.019 & 0.034 \\
Residential & 6.73 & 0.016 & 1.900 & 0.006 & 0.015 & 0.004 & 0.022 \\
Industrial & 6.49 & 0.039 & 1.762 & 0.007 & 0.081 & 0.063 & 0.066 \\
\hline \hline
\end{tabular}


Storm water in commercial land use area demonstrated the cleanest appearing storm water with lowest amounts of suspended solids. This land use sampling location also had other physical traits. It recorded the turbidity of all the different land use sites and lowest turbidity variance of all the different land use sites. With a low variance for suspended solids and turbidity, commercial sites are reasonably predictable and the results also demonstrate that there is a link between suspended solids and turbidity within storm water. Also the lowest nitrate and the highest nitrite concentration are recorded in commercial areas. Nitrite recorded the highest variance indicating that parameter can be unpredictable concentration in the storm water.

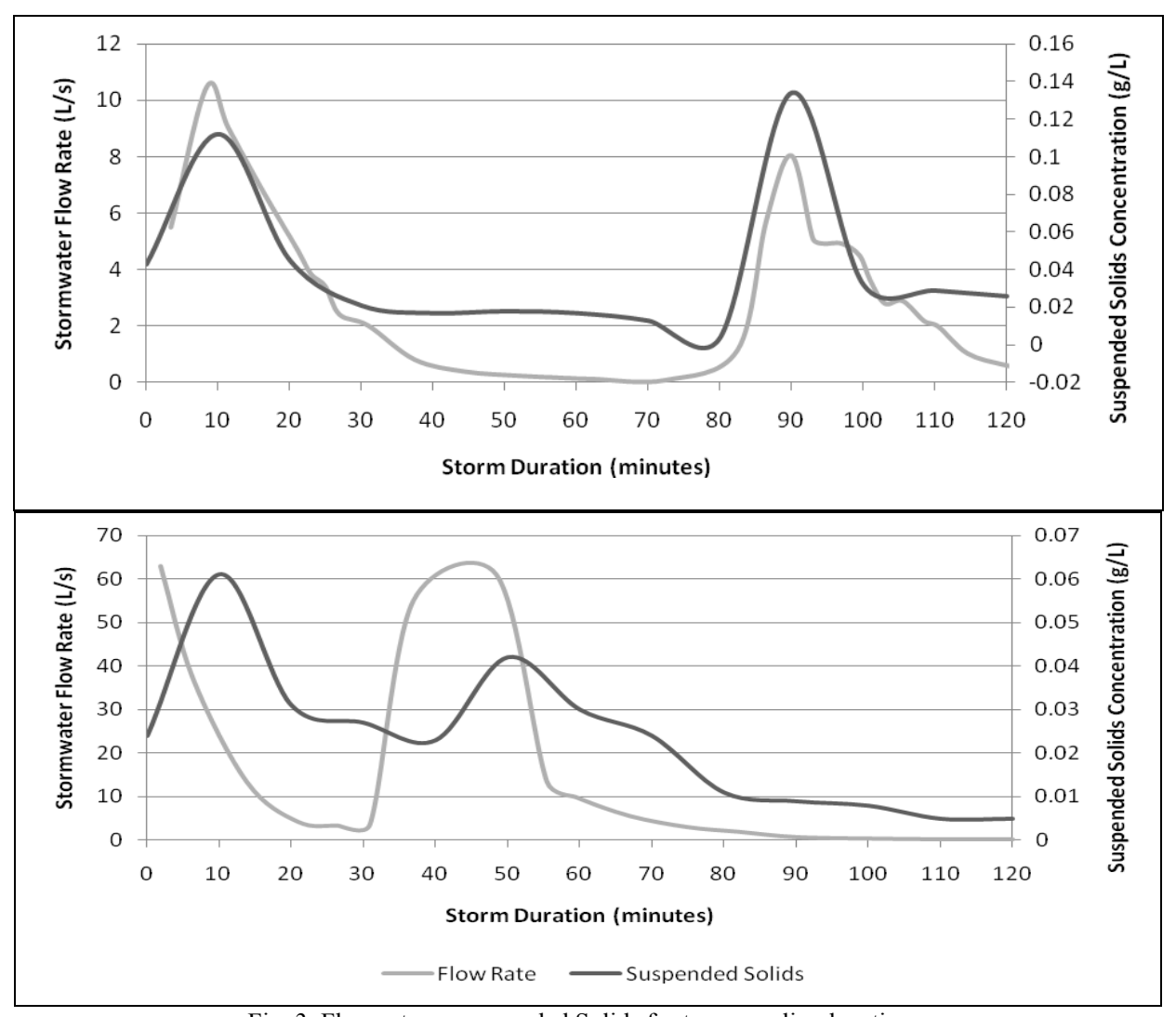

Fig. 3. Flow rate vs. suspended Solids for two sampling locations.

Residential land was demonstrated low levels of ammonia present in the storm water at some point in time while also recording the lowest minimum phosphate concentration in the storm water samples collected. Residential storm water resulted in containing low nitrate concentration and recorded low nitrate concentration. The residential site was one of many sites that demonstrated zero levels of ammonia present in the storm water at some point in time. This site also recorded the lowest concentration of ammonia in storm water. This indicates that the presence of ammonia in residential storm water is usually predictable and in low amounts.

The industrial storm water sampling location also had the dirtiest appearing storm water quality. This is due to recording the highest amounts of suspended solids in the storm water when compared to the other land use locations results. The results also demonstrate that there is a link between suspended solids and turbidity within storm water. The nutrient amounts in industrial sampling location also showed some features unique to the industrial site. This is the only site to record a zero concentration of nitrate in the storm water at some point in time. The industrial location also recorded the highest nitrate, ammonia and phosphate over all the storm water sampling locations.

The comparison of maximum, minimum and average recorded concentrations for suspended solid, turbidity, Nitrite, Nitrate, Ammonia and phosphorus are shown in Fig4.

\section{V.STORM WATER QUALiTy MANAGEMENT PRACTICES AND PROCEDURES}

Most of the local authorities are responsible for storm water quality management and improvement procedures. Therefore local authorities, especially local city councils are conducting several programs for the improvement of storm water quality. Develop and follow Storm water Quality Improvement Strategy Plans (WQISP) is one of the common practices in related authorities. Quality Improvement Strategy Plans (WQISP) are documents that detail policies, strategies and regulations for storm water quality improvement in a defined areas. These plans provide a ways of prioritizing recommendation and resources to improve storm water quality in authorities. Several research have been highlighted in the literature in drafting storm water quality improvement strategies, which are used by local city council officers, managers and decision makers as technical guidelines in developing storm water quality management procedures [14]. 

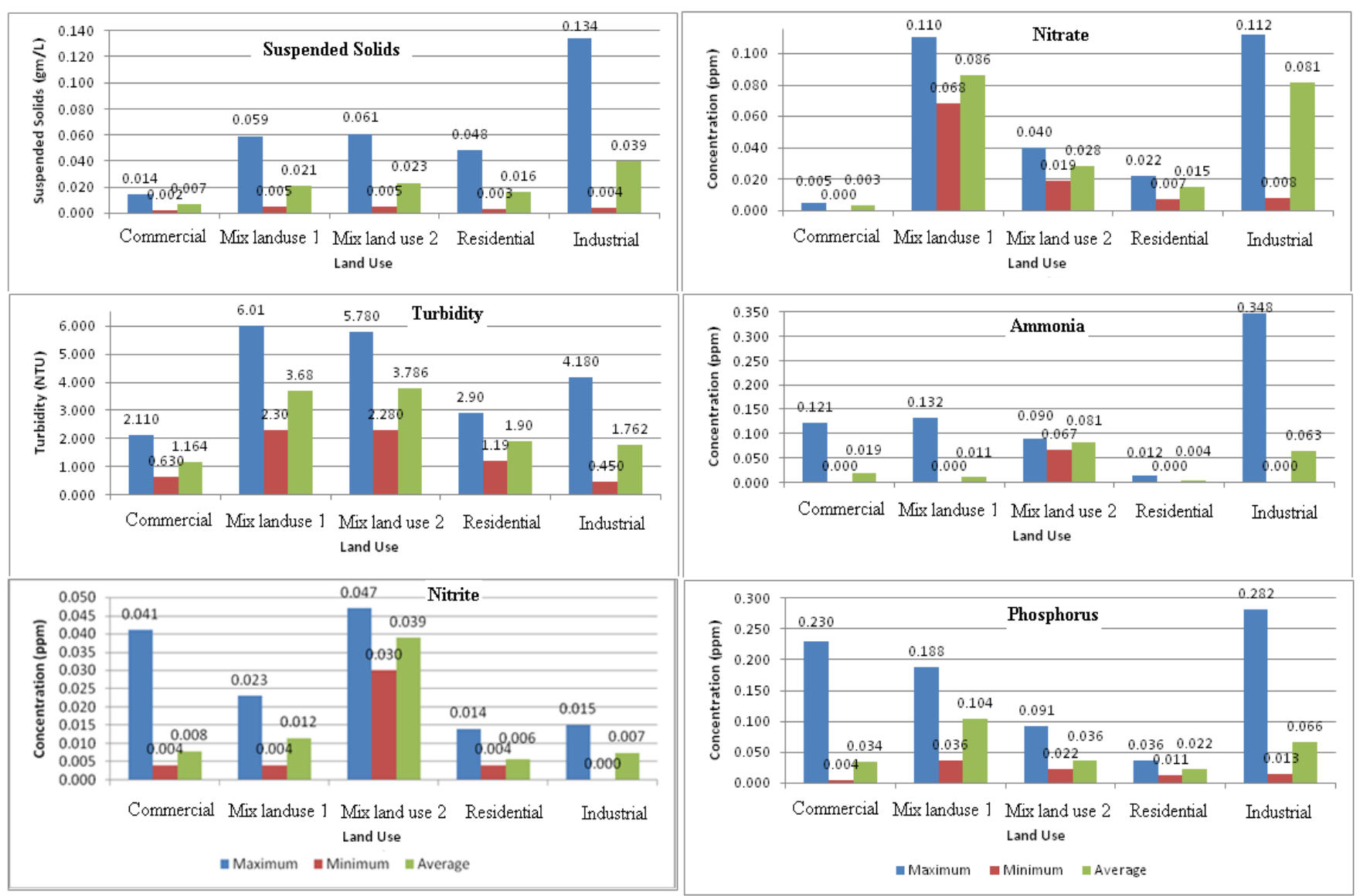

Fig. 4. Comparison of water quality parameters in different land use areas.

Most of the storm water quality management and quality improvement processes consider three basic quality control procedures; structural, non-structural and management control. Selection criteria of the control method vary based on the identified pollutions and management locations.

\section{A. Structural Controls}

Most of the urban catchments are controlled by structural controlling methods even though it is the most expensive method. The following structural control methods are common in managing the storm water quality.

- Gross Pollutant Traps (GPT) -Source control is an effective way of treating the storm water. GPTs can be employed in achieving source control for gross pollutants. The hotspots within catchments should be identified for the construction of new GPTs.

- Buffers - Buffers can be used to minimize polluted storm water runoff entering receiving environments such as rivers and lakes. Also, buffer strips can be used around constructed wetlands and other storm water treatment infrastructure to reduce the frequency of maintenance due to sediments and litter.

- Bio-retention System - Bio-retention systems include rain gardens and retention basins. Main purpose of constructing rain gardens is to uptake the excessive nutrients in storm water runoff which will then be used for growth of vegetation.

- Vegetated Swales - Swales can be constructed either sides of roads as road reserves to minimize runoff from major roads. Vegetated swales are effective in sites where the longitudinal slopes are steeper.

- Porous Pavements - Porous pavements are similar to vegetated swales. Local authorities can implement these porous pavements in low traffic areas such as car parks and driveways.

- Wetlands -The management and maintenance of wetlands should be properly carried out by the local authorities. Regular maintenance of wetland is required to avoid the growth of unnecessary aquatic plants.

\section{B. Non-structural Controls}

Lack of community awareness of the importance of storm water quality is an issue which can be solved by introducing education campaigns. The following education campaigns can be commenced in local councils.

- Fertilizer Wise Programs - These programs targets people awareness in order to reduce the amount of fertilizer in storm water runoff. It is aimed to reduce fertilizer application in residential gardening. It also suggests the growth of native plants and type of fertilizer to be used for each soil type. This will also prepare community to adjust to decreased water usage due to climate change limitations.

- Green Gardening Program - The residents can be educated about alternative landscaping techniques which reduce the use of fertilizer. Local authorities and state governments can 
initiate the program by providing free gardening classes and donating plants for residents in the houses closer to waterways and surface water bodies, as they would have a significant impact on storm water quality compared to other residents.

- Business Education Campaigns - The purpose of these campaigns are to educate the industrial and commercial sectors. This is very useful for regions which contain larger proportion of industrial and commercial lands. The campaign can be targeted to ensure the business organizations comply with the existing storm water management guidelines.

\section{Management Controls}

- Maintenance and Cost -Maintenance of roads, street sweeping, litter collection and maintenance of storm water network is essential in improving the storm water quality. The maintenance of vegetated swales, buffers and rain gardens include watering them during dry periods, gross pollutant removal, weed control and litter removal. The cost of maintenance can be reduced by using native plants in vegetated swales, buffer strips and rain gardens which require less attention and fertilizer. Reduction of maintenance can be achieved by using biodegradable erosion control matting in swales.

- Managing information - The absence of a database is an issue when considering the storm water treatment measures. A master database consisting locations, capacities, design drawings, dimensions and other technical information about the area's structural storm water management as well as the other useful information for the staff should be compiled for the use within the local authorities.

- Water quality monitoring - Water quality monitoring in different locations incorporating all the land use types, is important in understanding the water quality issues.

Proper understanding of impacts of land use patterns on storm water quality will enhance the development of storm water quality management and quality improvement processes taking structural, non-structural and management quality control procedures into account. Therefore outcome of this study will assist authorities, decision makers and policy developers to come up with sustainable land use management concepts to ensure water quality protection.

\section{Conclusions}

Storm water runoff quality is an important aspect of natural water cycle. The main factor affecting the storm water quality as identified during this study is land use types. To understand the impacts of land use pattern on storm water quality, storm water samples have been tested in three main land use areas; residential, commercial and industrial lands around the Town of Victoria Park in Western Australia. The results show very interesting patterns. Time variation of storm water flow, rainfall intensity and storm water quality clearly showed that the highest peak in storm water contaminants occurs after the beginning of the storm event which is referred to as the first flush event, where the majority of pollutants are washed down with the initial precipitation runoff. The highest nitrite concentration was recorded in commercial lands. The industrial storm water had the dirtiest appearing storm water quality showing the highest amounts of suspended solids. Residential storm water shows the lowest nitrate, ammonia and phosphate concentrations.

A general recommendation concluded from this study is that pollutant traps be incorporated into Western Australia's drainage network by incorporating some new infrastructure into the current drainage networks. Compensation basins can improve quality of the storm water entering it using items purposely designed with the intension of improving the storm water quality including sedimentation ponds, litter traps or wetlands. Also, the first flush of storm water is diverted away from natural waterways as the results indicated that the initial first flush of storm water that contains higher levels of both physical and chemical contaminates. Another general recommendation is that industrial land use areas storm water do not enter natural waterways as the results of this project demonstrate that the industrial land use sites have the worst storm water quality.

The storm water improvement strategies suggested in this study includes non- structural, structural and management controls. The drains need regular maintenance and attention in order to prevent the pollution in receiving water environments. The gross pollutants should be trapped prior to discharging into receiving water environments. It is identified that non-structural and management controls contribute to larger improvements in storm water quality. The community involvement in the identification process is very useful and cost effective. Public education campaigns can be introduced to control the fertilizer usage. The lack of maintenance of structural controls indicates the lack of understanding of the importance of storm water management. Preparing proper maintenance plans with detailed maintenance steps will assist in achieving the best possible outcome from above mentioned water quality improvement and control methods.

\section{REFERENCES}

[1] H. Ha, and M..K. Stenstrom,. Identification of land use with water quality data in storm water using a neural network, Water Research , vol.37(17), pp 4222-4230, 2003

[2] A. Goonetilleke, E. Thomas, S. Ginn, and D. Gilbert, Understanding the role of land use in urban storm water quality management, Journal of Environmental Management, Vol 74(3), pp 31-42, 2005

[3] K.J. Hall, and B.C. Anderson, The toxicity and chemical composition of urban storm water runoff, Canadian Journal of Civil Engineering, vol 15, pp 98-105, 1986

[4] T.J. Lopes, K.D. Fossum, J.V. Phillips, J.E. Monical, Statistical summary of selected physical chemical, and microbial characteristics and estimates of constituent loads in urban storm water Maricopa Count, Arizona. Water-Resources Investigations Report 94-4240. US Geological Survey, 1995.

[5] J.T.C. Parker, K.D. Fossum, and T.L. Ingersol, Chemical characteristics of urban storm water sediments and implications for environmental management, Environmental Management, vol 26, pp99-115, 2000

[6] M. Shinya, T. Tsuchinaga, M. Kitano, Y. Yamada, and M. Ishikawa, Characterization of heavy metals and polycyclic aromatic hydrocarbons in urban highway runoff, Water Science and Technology, vol 42 (2), pp201-208, 2000.

[7] R.T. Bennerman, D.W. Owens, R.B. Dodds, N.J. Hornewer. Sources of Pollutants in Wisconsin Stormwater. Water Science and Technology. Vol 28 (3-5), pp241-259, 1993. 
[8] L. A. Corson, Development of Strategy for Preparing an Indot Storm water Quality Management Plan. 2004.

[9] J.K. Gilbert, J.C. Clausen., Storm water runoff quality and quantity from asphalt, paver and crushed stone driveways in Connecticut. Water Research, vol 40(4) pp.826-832, 2006

[10] K. Alsharif. Construction and storm water Pollution: Policy, violations, and penalties, Land Use Policy, vol 27(2), pp. 612-616, 2010

[11] APHA, American Public Health Association, Standard Methods for the Examination of Water and Wastewater, American Water Works Association, Water Environment Federation, Virginia. 2005, (CD-ROM)

[12] Australian Bureau of Statistics, Regional Population Growth, Australia, 2007-2008, 2009.

[13] Town of Victoria Park (www.vicpark.wa.gov.au)

[14] R. Sarukkalige and D. Gamage, "Development of storm water quality improvement strategy plan for local city councils in Western Australia", in Proc Int Conf on Sustainable Water Resources, Venice, Italy, Nov 2011 (in press).

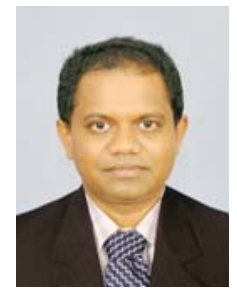

Ranjan Sarukkalige is a senior lecturer in Civil Engineering at Curtin University, Australia. He completed his Bachelor degree in the field of Civil Engineering from University of Peradeniya, Sri Lanka and M.Eng degree from the Asian Institute of Technology (AIT), Thailand. He also completed his $\mathrm{PhD}$ in Civil Engineering at Tohoku University in Japan. He has over 10 years research and teaching experience in Civil Engineering including lecturer at University of Ruhuna Sri Lanka, Post doctoral fellow at Tohoku University Japan. His research interests are mainly in water resources engineering especially in hydrology, storm water management and climate change impacts. He has published more than 30 research publications including the book titled "Effects of global warming on coastal groundwater resources", which has attracted significant attention among the professional and the community. Dr. Sarukkalige is a senior member of Asia-Pacific Chemical, Biological \& Environmental Engineering Society (APCBEES).

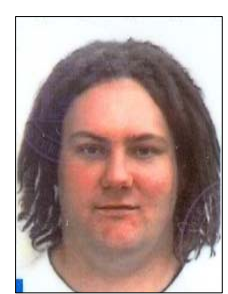

Shane Priddle is a Civil Engineer in the Infrastructure Design branch of the Water Corporation in Western Australia. He completed his Bachelor degree in the field of Civil Engineering from Curtin University, Australia. Mr. Priddle studied on 'assessment of storm water quality in different land use areas" for his bachelor thesis which is contributed to this publication. His present research interests are mainly in Water Resources Engineering especially in water resources design, related infrastructure design and hydraulic design, and storm water management.

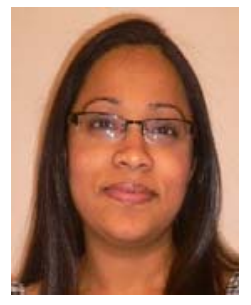

Dinushi Gamage is a Civil Engineer in the Tactical Asset Management branch of the Water Corporation in Western Australia. She completed her Bachelor degree in the field of Civil Engineering from Curtin University, Australia. Her research interests are mainly in Water Resources Engineering especially in water resources design, related asset management and storm water management. Her expertise also lies in the area of water quality improvement and management, and policy development. 